\title{
Putting a federal capacities assessment to work: blueprint for a national program for the early detection of and rapid response to invasive species (EDRR)
}

\author{
Jamie K. Reaser $(\mathbb{C}$
}

Received: 3 November 2019/Accepted: 3 November 2019/Published online: 31 December 2019

(C) The Author(s) 2019

\begin{abstract}
This paper responds to national policy directives intended to improve the US government's capacity to protect national security from the adverse impacts of invasive species. It is the final, synthesizing contribution to a Special Issue of Biological Invasions comprising 12 papers that collectively inform the development and implementation of a national program for the early detection of and rapid response to invasive species (EDRR). The blueprint sets forth policies, goals, and actions to be taken by relevant Executive Branch agencies and components of the Executive Office of the President to develop a national EDRR program, appropriations permitting. It is designed to function as guidance for advancing federal policy through Presidential, Secretarial, and/or Congressional directives. Those committed to protecting national security, the economy, and the well-being of American people are forewarned that our ability to establish a national EDRR program is undermined by the diminishment of the federal workforce; institutional structures, policies, and programs; and directly applicable leadership mechanisms, including the National Invasive Species Council, Invasive Species Advisory Committee, and their managerial Secretariat.
\end{abstract}

J. K. Reaser ( $\square)$

Center for Large Landscape Conservation, 303 W

Mendenhall St \#4, Bozeman, MT 59715, USA

e-mail: jamiekreaser@gmail.com
Keywords Detection - Response $\cdot$ EDRR $\cdot$ Invasive species $\cdot$ Federal capacities

\section{Introduction}

A comprehensive approach to biosecurity encompasses a full range of risk management practices intended to defend against harmful and potentially harmful biological organisms, the vast majority of which are invasive species (Meyerson et al. 2009). The US government defines an invasive species to mean, "with regard to a particular ecosystem, a non-native organism whose introduction causes, or is likely to cause, economic or environmental harm, or harm to human, animal, or plant health" (Executive Office of the President 2016). Three presidential executive orders (EO) have explicitly recognized and focused on the threats posed to national security by harmful non-native species, tasking federal agencies to take a high-level, coordinated, and cost-efficient approach to invasive species prevention, eradication, and control (Executive Office of the President 1977, 1999, 2016). Many other presidential directives have complemented these executive orders, reinforcing national security concerns and establishing action plans for specific sectors. For example, the White House Council on Climate Preparedness and Resilience's priority agenda (Climate and Natural Resources 
Working Group 2014) recognized the need to mitigate invasive species as an ecosystem stressor and called for a national approach to improving invasive species detection and response capacities (published as US Department of the Interior 2016). Although the linkages are not explicitly acknowledged, the National Biodefense Strategy (Executive Office of the President 2018) focuses on invasive pathogens and was informed by the US Invasive Species Advisory Committee (ISAC)'s briefing paper on invasive species impacts on wildlife health (ISAC 2018).

The 12 papers in this Special Issue of Biological Invasions deliver on a 2016-2018 National Invasive Species Council (NISC) Management Plan (National Invasive Species Council 2016) priority action calling for “...scientific, technical, and institutional assessments in order to determine the capacities and resources necessary to establish a national early detection and rapid response program..." (hereafter, "federal capacity assessments"). They also advance two of the seven duties set forth for NISC implementation in EO 13751 (Executive Office of the President 2016):

- advance national incident response, data collection, and rapid reporting capacities that build on existing frameworks and programs and strengthen early detection of and rapid response to invasive species, including those that are vectors, reservoirs, or causative agents of disease, and

- support and encourage new technologies and practices, and promote the use of existing technologies and practices, to prevent, eradicate, and control invasive species...

In the first overview paper of the series, Reaser et al. (2019a, this issue) define the early detection of and rapid response to invasive species (EDRR) as a guiding principle for minimizing the impact of invasive species in an expedited yet effective and cost-efficient manner, where "detection" is the process of observing and documenting an invasive species, and "response" is the process of reacting to the detection once the organism has been authoritatively identified and response options have been assessed (i.e., risk and feasibility screening completed). Recognizing that EDRR is a non-linear, iterative process, the authors present a conceptual framework that portrays EDRR as the tenet for an integrated system (Fig. 1) rather than a step-wise set of components addressed in a linear manner, as has been typical of other EDRR frameworks (see discussion in Reaser et al. 2019a, this issue). The paper concludes with a short list of cross-cutting, catalytic actions to establish the foundation of a national EDRR program. The ten following papers in the series address specific components of the framework.

Here, I synthesize the primary needs identified by the federal capacity assessments into a blueprint for developing a national EDRR program. Figure 1 is to be referenced as the organizational framework for the paper. The papers in the Special Issue that explicitly identify the need for and/or guide federal actions are referenced within the blueprint. In content and format, the blueprint is explicitly designed to function as guidance for advancing federal policy through Presidential, Secretarial, and/or Congressional directives.

The survey of federal agency EDRR programs and capacities on which the assessments are based was substantially lacking in response from some agencies and on certain topics (see discussion in Reaser et al. 2019a, this issue). Although the NISC Secretariat staff and contractors augmented this information as feasible, resource limitations necessarily resulted in assessment gaps. In particular, the assessment team was not able to evaluate fully the effectiveness of existing EDRR programs, capacities of federal institutional frameworks (see Burgos-Rodríguez and Burgiel 2019a, this issue), types of response measures used and their effectiveness across taxa and context, or the applicability of the wide range of federal and federally-funded biodiversity inventory and monitoring programs to EDRR. The assessment authors also recognized the need to develop a feasibility screening process and associated decision support tool(s) (Reaser et al. 2019a, this issue).

When implementing the blueprint, agencies must consider at least four, potentially inter-related, needs for technical and institutional flexibility: spatio-temporal scale, taxa, available resources (particularly personnel and budget), and socio-political receptivity. Although the papers in our series make this point from various perspectives, none of the papers explicitly focus on these parameters. In large part, this reflects the lack of complete and in-depth response from relevant agencies. It is also an artifact of the tendency of technical journals to focus on scientific research rather than management approaches and their 


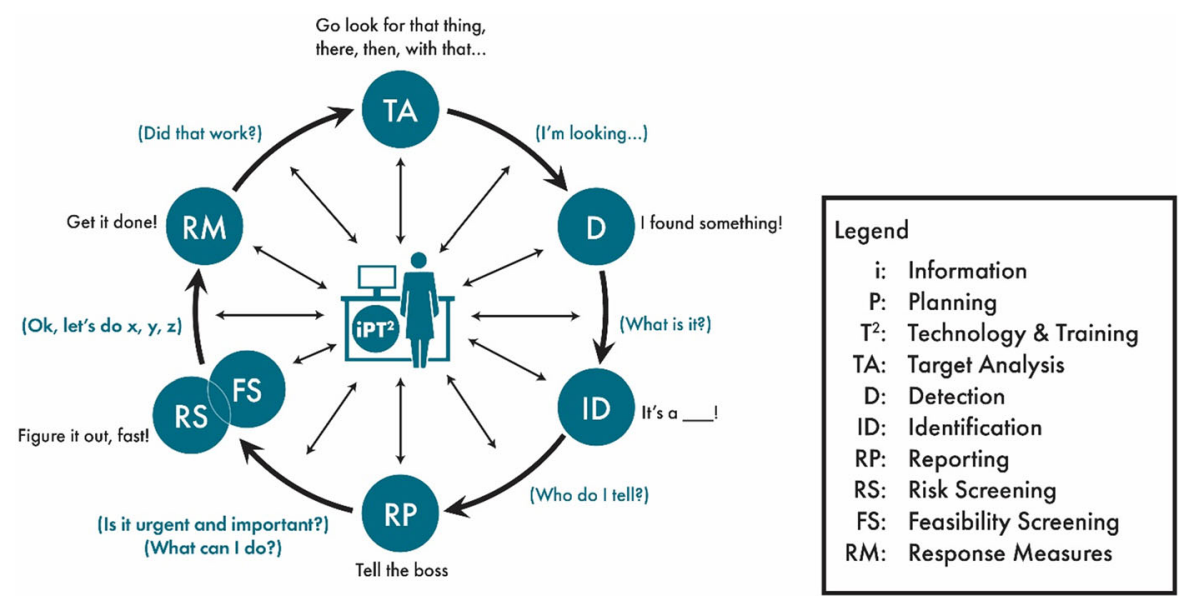

Fig. 1 EDRR: a comprehensive system. In this model, the blue circles represent the primary actions (components) that need to be enacted in a step-wise manner for the effective detection of and response to a biological invasion. A legend clarifies the meaning of the letters in the circles. The associated commentary reflects the primary questions, observations, and directives that guide the process from one component to the next. At the core of the process, represented by the person and work station, are the

outcomes. Action items to help fill aspects of these information gaps are included in the blueprint.

\section{The blueprint}

\section{Purpose}

The United States must sustain and expand efforts to protect national security, the economy, and the American people from the adverse impacts of invasive species across all sectors of society. Ideally, invasive species are detected and responded to along invasion pathways into the country or at our national borders, prior to entering the country. The federal government bears primary leadership responsibility for these actions. When these pathway management and border control efforts fail to intercept harmful or potentially harmful non-native species, the costs of action increase dramatically and the burden of defense falls upon land management and transportation agencies across all levels of government, the private sector, and the public. A high-level, whole-of-government approach is thus needed to facilitate the collaboration, communication, cost-efficiencies, and innovation necessary for effective EDRR. informational and technical inputs necessary for the system to function. Arrows point in both directions in an effective system because the information and other outputs generated by one component are strategically used by other components. As is true of all models, this is a simplified depiction of reality; implementation of EDRR is a complex, iterative process that requires context-specific adaptation

\section{Policy}

The federal government must coordinate and use applicable federal frameworks, investments, assets, and expertise to detect and respond to invasive species incursions in an effective and cost-efficient manner. Fundamentally, this requires agencies to support and facilitate access to the information, planning, technologies, and training that enable EDRR. In order to secure national assets and the well-being of Americans, federal agency actions must take into consideration and complement preparedness, planning, and implementation efforts of other countries; state, territorial, tribal, and local governments; non-governmental organizations; the private sector; and the general public.

Goals

Consistent with Executive Orders 13112 and 13751 and other relevant national directives, the heads of federal agencies and relevant components of the Executive Office of the President (collectively, Agencies) shall, to the maximum extent permitted by law and other logistical feasibilities, carry out aforementioned policy by enabling and enacting actions to achieve the following EDRR capacity goals: 
(a) Coordination, integration, and communication Agencies shall improve the coordination, integration, and communication of EDRR-related activities to enhance the collective benefits of federal programs and investments, as well as to strategically complement and integrate activities across Agencies and with state, territorial, tribal, and local officials. A key aspect of EDRR communication is the timely and accurate reporting of invasive species observations and interceptions, as well as anticipating and communicating the scale of potential spread and impact.

(b) Legal and institutional capacity building Agencies shall complement, harmonize, and expand the legal and institutional frameworks necessary to enable the rapid detection of and response to invasive species incursions prior to, upon, and after entry into the United States. This includes, but is not limited to, establishing cooperative agreements for invasive species EDRR among jurisdictional institutions from local to international scales of authority.

(c) Planning and decision support Agencies shall support EDRR-related planning approaches (including Incident Command Systems, and decision support tools, such as target analysis, risk screening, feasibility screening, watch lists) to increase the speed and effectiveness of invasive species detection and response measures.

(d) Data collection, mobilization, and analysis Agencies shall collect and share EDRR-relevant information (including data on non-native species occurrence, identification, biology, risks and impacts, response options and effectiveness), mobilizing it into an inter-operable, openaccess, national invasive species information infrastructure (including databases, clearinghouses, and analytical and depiction tools) to strengthen the decision-making capacities required for timely detection of and effective responses to invasive species incursions.

(e) Scientific, technical, technological capacity building Agencies shall enhance EDRR efforts by carrying out and supporting relevant research, technology innovation and transfer, and technical training, including by addressing impediments to taxonomic capacity and fostering contributions from citizen scientists as an urgent matter.

(f) Response measures Agencies shall facilitate and expand capacities to respond rapidly and effectively to invasive species incursions by addressing any barriers associated with legal and institutional frameworks, planning and coordination, decision support, and technological or technical capacity, as further described in goals a-e.

Actions

To further the aforementioned policies and goals, as made feasible by the availability of appropriations, Agencies should act cooperatively as follows:

(a) Coordination, integration, and communication

(i) Create a glossary of EDRR-relevant terms; examine term ambiguities, inconsistencies, and flexibilities; and harmonize or standardize terms as feasible, communicating and institutionalizing these terms to facilitate their understanding and application (Burgos-Rodríguez and Burgiel 2019b, this issue; Reaser et al. 2019a, this issue).

(ii) Develop and routinely update a publicly-accessible EDRR operational plan that demonstrates the relevance of EDRR to Agency missions, as well as their authorities, roles, and responsibilities relevant to EDRR components (Fig. 1). Include contact information for authoritative focal points (Reaser et al. 2019a, this issue).

(iii) Undertake and publicly report the findings of an inventory of Agency assets for supporting a national EDRR program, including programs currently focused on addressing invasive species and those programs that could be costeffectively modified to expand federal capacities for addressing invasive species (e.g., inventory and monitoring programs currently focused on native 
species) (Meyers et al. 2019, this issue; Reaser et al. 2019a, this issue).

(iv) Taking (a-iii) into consideration, resume and enhance the EDRR crosscut budget, making it applicable to the effective leveraging of existing agency resources and development of multiagency funding proposals to address common needs for additional resources.

(v) Establish flexible yet binding agreements and other coordinating mechanisms among federal agencies, as well as with all others who bear responsibilities for the management of invasion pathways and recipient ecosystems. The arrangements should detail resource-sharing, delineation of authorities, communications protocols, and sharing of personnel and subject matter experts (Burgiel 2019, this issue; Lyal and Miller 2019, this issue).

(b) Legal and institutional capacity building

(i) Delineate and communicate a national legal and institutional framework for enabling the early detection of and response to invasive species across taxa and geographies. The framework should support Agencies to act in accordance with Executive Orders 13112 and 13751, as well as other complementary executive guidance (Burgos-Rodríguez and Burgiel 2019a, b, this issue; Lyal and Miller 2019, this issue; Reaser et al. 2019a, this issue).

(ii) Analyze and publicly report on Agency authorities and mechanisms for authority (such as compacts, enforcement agreements, good neighbor authority, interagency agreements, international agreements, memoranda of understanding and agreement, technical and financial assistance) for their ability to facilitate and/or serve as barriers to implementing a national EDRR program. This should include explicit invasive species authorities and mechanisms, as well as a wide range of permitting and enacting authorities and associated mechanisms (including compliance waivers and protocols) that could be applied at an Agency's discretion (Burgos-Rodríguez and Burgiel 2019a, b, this issue).

(iii) Harmonize and streamline authorities and associated mechanisms, giving priority attention to environmental compliance agreements, to expedite EDRR and increase operational costefficiencies (Burgos-Rodríguez and Burgiel 2019a, b, this issue).

(iv) Establish authorities and associated mechanisms to fill gaps in the national and legal institutional framework, including to provide emergency designation of harmful or potentially harmful non-native species without additional delays for issuing regulations or processing undue assessments before enacting EDRR (Burgos-Rodríguez and Burgiel 2019a, b, this issue).

(v) Direct Agency solicitors to evaluate, interpret, and provide opinions on discretionary powers to address EDDR under Agency authorities, giving particular consideration to whether current actions and programs can be used synergistically for EDRR and how emergency authorities and associated resources can be applied to EDRR (Burgos-Rodríguez and Burgiel 2019b, this issue).

(c) Planning and decision support

(i) Develop invasive species response or contingency plans that incorporate Incident Command System principles and protocols to be applied by incident management teams operating along invasion pathways, at ports of entry, and across regional scales (Burgiel 2019, this issue; Morisette et al. 2019, this issue).

(ii) Regularly conduct table-top and infield exercises to identify gaps, obstacles, and other planning needs, 
including clarification of issues around authorities, resources, communications, and logistics (Burgiel 2019, this issue).

(iii) Develop and communicate performance metrics for EDRR decision support tools (including target analysis, risk screening, feasibility screening, and watch lists), recognizing that different ecosystems, pathways, and taxonomic groups may require separate but complementary approaches (Meyers et al. 2019, this issue; Morisette et al. 2019, this issue; Reaser et al. 2019c, this issue).

(iv) Conduct, report on, and enact the findings of a needs assessment for standardizing, strengthening, and expanding use of science-based decision support tools within and across Agency EDRR programs, including providing sufficient staffing for conducting decision support analyses, applying advanced technologies, and making tools and their outputs publicly accessible through decision support toolkits consistent with regulatory approaches (Martinez et al. 2019, this issue; Meyers et al. 2019, this issue; Morisette et al. 2019, this issue; Reaser et al. 2019c, this issue).

(v) Along invasion pathways into the United State and at national borders, prioritize planning and decision support for species new to trade or increasing in trade popularity to reduce propagule pressure and the burden of response (Meyers et al. 2019, this issue; Morisette et al. 2019, this issue; Reaser et al. 2019c, this issue).

(d) Data collection, mobilization, and analysis

(i) Facilitate greater access to the information required for EDRR decision-making by establishing and supporting userfriendly, open access, centralized, searchable clearinghouses that include relevant authorities and authorizing mechanisms, planning protocols and supporting information, decision support tools and analyses, reports on the effectiveness of response measures, and training course curricula. The clearinghouses should be integrated with relevant local, regional, national, and international databases, as well as their associated analytical and data depiction tools (Burgiel 2019, this issue; BurgosRodríguez and Burgiel 2019b, this issue; Lyal and Miller 2019, this issue; Meyers et al. 2019, this issue; Morisette et al. 2019, this issue; Reaser et al. 2019a, b, c, this issue; Wallace et al. 2019, this issue).

(ii) Establish a coordinated framework of interoperable information systems, recognizing that information systems not initially designated for EDRR may be applicable (Lyal and Miller 2019, this issue; Meyers et al. 2019, this issue; Reaser et al. 2019b, this issue; Wallace et al. 2019, this issue).

(A) In order to operationalize the coordinated information framework, Agencies should:

a. Establish a government-wide invasive species data management policy for designated data custodial roles and management responsibilities from agency to programmatic levels, address relevant legal and policy issues (including privacy and security), and institutionalize invasive species information management guidelines. The policy should be authoritative and specific enough for agencies to discern their obligations, address sensitive datasharing concerns, and direct the mobilization of federal data into publicly available information systems, yet sufficiently flexible to account for unanticipated needs and emerging opportunities 
(Reaser et al. 2019b, this issue; Wallace et al. 2019, this issue).

b. Identify, improve, and sustain federal information systems that are vital to the operation of a national EDDR program, assess their relationships (e.g., for duplicative or integrative functions), and develop and implement a plan for improving, sustaining, and making these systems more cost-effective over the long-term. This should including building the capacity to join datasets to improve biological, geo-spatial, and socio-economic analyses (Reaser et al. 2019b, this issue).

c. Identify, develop, and support relevant data standards, including those that delineate critical aspects of invasive species biology and population parameters needed to distinguish which nonnative species are invasive and priorities for response measures, North American Invasive Species Management Association mapping standards, and metrics for capturing the environmental and socio-economic impacts of invasive species (Wallace et al. 2019, this issue).

d. Establish an agreement for data sharing among the primary information systems for non-native species occurrence data in the United States (Wallace et al. 2019, this issue).

e. Mobilize non-native species occurrence data into publicly accessible central data integrators/aggregators that are coupled with appropriate analytical and decision support tools, using the Biodiversity Information Serving Our Nation (BISON) information system (https://bison.usgs.gov, accessed 19 September 2019) and interoperable data sources. Facilitate this effort by developing and implementing an ongoing national campaign for non-native species data collection and mobilization (Morisette et al. 2019, this issue; Reaser et al. 2019b, this issue; Wallace et al. 2019, this issue).

f. Encourage databases serving taxonomic names, such as the Integrated Taxonomic Information Service (ITIS) (https://www.itis. gov/, accessed 25 September 2019) to address gaps in taxonomic groups that have a high propensity for invasiveness as a matter of priority (Wallace et al. 2019, this issue).

g. Foster the development and sharing of EDRR-relevant analytical and data depiction tools, including tools for specialized data searches, mapping and other spatial analyses, species identification, decision support, and response evaluation (Martinez et al. 2019, this issue; Reaser et al. 2019b, this issue).

h. Continue US engagement in international information standard-setting bodies, frameworks, and platforms, including the Global Biodiversity Information Facility (GBIF; https://www.gbif.org, accessed 19 September 2019).

(B) In order to enhance the information content accessible through the coordinate information framework, Agencies should as a priority:

a. Make federal pathway and ports-ofentry non-native species intercept data publicly accessible to the extent legally feasible (Reaser et al. 2019b, this issue).

b. Incorporate and enable analysis of species-in-trade data (including 
species, quantities of imports, and countries of origin and transit) that are contributed by industries or by harvesting non-native species trade data from social media via web crawling tools (Meyers et al. 2019, this issue).

c. Include information on invasive species impacts and management options, including their effectiveness (Wallace et al. 2019, this issue).

d. Facilitate ready access to biological data that enable detection and response technology development by, for example, building and linking to genetic libraries (DNA fingerprinting) to enable identification tool development and cell lines of current and potential invaders to allow in vitro screening of potential control agents (Lyal and Miller 2019, this issue; Martinez et al. 2019 , this issue).

(e) Scientific, technical, and technological capacity building

(i) Further our knowledge of species biology, ecology, and impacts, including the implications of interactions among species, spatio-temporal variation in risks, and interactions between invasive species and other drivers of environmental change (Reaser et al. $2019 b$, this issue; Meyers et al. 2019, this issue; Morisette et al. 2019, this issue).

(ii) Advance invasive species detection and response technologies, collecting and sharing data on their efficacy. Give priority to surveillance, identification, and response tools that are socially acceptable, cost-efficient, and effective for multiples species and contexts. Facilitate this work by supporting a culture of innovation and communities of practice (Martinez et al. 2019, this issue; Morisette et al. 2019, this issue).

(iii) Increase and modernize research facilities to advance new technological response measures in a manner consistent with changing regulations, new approaches, study replication needs, and regional efficiencies (Lyal and Miller 2019, this issue; Martinez et al. 2019, this issue).

(iv) Maximize and expand technical staff capacities by detailing staff between agencies, creating interagency collaboratives, and expanding partnerships with nonfederal institutions, particularly with the private sector or academia (Lyal and Miller 2019, this issue; Martinez et al. 2019, this issue).

(v) Support citizen science initiatives and open-access, low-cost detection, identification, and reporting tools for public application to EDRR (Lyal and Miller 2019, this issue; Martinez et al. 2019, this issue).

(vi) Promote, as a matter of urgency, adequate taxonomic and identification expertise and associated financial and technical resources, including standardized identification protocols, at all scales (Lyal and Miller 2019, this issue).

(vii) Ensure long-term sustainability of biological reference collections, including representatives of specimens from native and introduced ranges linked to evidence of impact where feasible (Lyal and Miller 2019, this issue).

(viii) Support and further the use of prizes and challenges to encourage technology development and dualuse application for invasive species of high priority concern (Martinez et al. 2019, this issue).

(ix) Require routine and consistent training for appropriate field-level 
and management staff, giving particular attention to identification capacity, Incident Command System operation, and emerging technology application (Burgiel 2019, this issue; Lyal and Miller 2019, this issue; Martinez et al. 2019, this issue).

(f) Response measures

(i) In removing barriers to response capacity by implementing the relevant actions identified in (a)-(e), Agencies should also:

(A) Recognize, assess, and report on the dynamic socio-economic and cultural factors that influence response capacity (Reaser et al. 2019a, this issue).

(B) Incorporate the aforementioned factors into feasibility screening decision support tools (Reaser et al. 2019a, this issue).

(C) Develop science-based social marketing campaigns that address socio-economic and cultural barriers to response measure implementation (Reaser et al. 2019a, this issue).

\section{Conclusion and cautionary notes}

Despite numerous calls for a comprehensive approach to US biosecurity (Meyerson and Reaser 2002a, b, 2003), protecting the nation from the adverse impacts of invasive species remains an urgent and largely unaddressed policy need (Meyerson et al. 2019). If effectively harnessed, the growing interest in EDRR by government agencies and the public, particularly citizen scientists, could lead to developing a national EDRR program that vastly improves biosecurity. The Executive and Legislative branches have available the necessary reasoning, authorities, and mechanisms to transition the blueprint herein from concept to operational reality. However, there is a long history of federal government failure to clarify and prioritize EDRR-relevant programmatic needs, or to support the requisite frameworks and initiatives once these are identified (Reaser et al. 2019a, b, this issue; Simberloff et al. 2005). Furthermore, our ability to establish a national EDRR program is currently being undermined by the diminishment of the federal workforce; institutional structures, policies, and programs; and directly applicable leadership mechanisms, including the National Invasive Species Council (NISC), Invasive Species Advisory Committee (ISAC), and their managerial Secretariat (Meyerson et al. 2019; pers. obs.). We must either adequately invest in our nation's future or prepare for the extraordinary costs of the consequences, including major economic damage and lives lost.

Acknowledgements This paper advances action 5.1 of the 2016-2018 National Invasive Species Council (NISC) Management Plan. My sincere gratitude to the numerous contributors and collaborators who, over a 4-year period, made the Special Issue possible. In particular, I thank all of the members of the former National Invasive Species Council (NISC), NISC Secretariat, and Invasive Species Advisory Committee (ISAC) who understood the importance of a highlevel, whole-of-government approach to addressing invasive species and dedicated countless hours to achieving the intent of Executive Orders 13112 and 13751. Specifically, I recognize Robert Boyd, Kelsey A. Brantley, Genevieve Brune, Stanley W. Burgiel, Jhoset Burgos-Rodríguez, Amy Ferriter, Mark Frey, Jason Kirkey, Jeffrey T. Morisette, Sarah D. Veatch, and Michael Vissichelli as members of the NISC Secretariat who embodied "We can do this!". I am grateful to everyone who contributed to the NISC federal agency surveys and supplemental inquires that informed the papers in the Special Issue. My appreciation is also extended to Laura Meyerson, Dan Simberloff, Jacob Malcolm, Gary Tabor, Chris Lyal, Scott Miller, and Stas Burgiel for reviews that improved this manuscript.

Open Access This article is licensed under a Creative Commons Attribution 4.0 International License, which permits use, sharing, adaptation, distribution and reproduction in any medium or format, as long as you give appropriate credit to the original author(s) and the source, provide a link to the Creative Commons licence, and indicate if changes were made. The images or other third party material in this article are included in the article's Creative Commons licence, unless indicated otherwise in a credit line to the material. If material is not included in the article's Creative Commons licence and your intended use is not permitted by statutory regulation or exceeds the permitted use, you will need to obtain permission directly from the copyright holder. To view a copy of this licence, visit http://creativecommons.org/licenses/by/4.0/.

\section{References}

Burgiel SW (2019) The incident command system: a framework for rapid response to biological invasion. Biol Invasions. https://doi.org/10.1007/s10530-019-02150-2 
Burgos-Rodríguez J, Burgiel SW (2019a) Federal legal authorities for the early detection of and rapid response to invasive species. Biol Invasions. https://doi.org/10.1007/ s10530-019-02148-w

Burgos-Rodríguez J, Burgiel SW (2019b) Federal legal authorities: guidance for application to the early detection of and rapid response to invasive species. Biol Invasions. https://doi.org/10.1007/s10530-019-02149-9

Climate and Natural Resources Working Group (2014) Priority agenda: enhancing the climate resilience of America's natural resources. Council on Climate Preparedness and Resilience, Washington, DC. https://obamawhitehouse. archives.gov/sites/default/files/docs/enhancing_climate_ resilience_of_americas_natural_resources.pdf. Accessed 17 Sept 2019

Executive Office of the President (1977) Executive order 11987, 42 FR 26949 3CFR, 24 May 1999

Executive Office of the President (1999) Executive order 13112, 64 FR 6183-6186, 8 Feb 1999

Executive Office of the President (2016) Executive order 13751, 81 FR 88609-88614, 5 Dec 2016

Executive Office of the President (2018) National biodefense strategy. Washington, DC

Invasive Species Advisory Committee (2018) Reducing the risk of invasive pathogens to wildlife health in the United States. National Invasive Species Council Secretariat, Washington, DC

Lyal CHC, Miller SE (2019) Capacity of United States federal government and its partners to rapidly and accurately report the identity (taxonomy) of non-native organisms intercepted in early detection programs. Biol Invasions. https://doi.org/10.1007/s10530-019-02147-x

Martinez B, Reaser JK, Dehgan A, Zamft B, Baisch D et al (2019) Technology innovation: advancing capacities for the early detection of and rapid response to invasive species. Biol Invasions. https://doi.org/10.1007/s10530-01902146-y

Meyers NM, Reaser JK, Hoff MH (2019) Instituting a national early detection and rapid response program: needs for building federal risk screening capacity. Biol Invasions. https://doi.org/10.1007/s10530-019-02144-0

Meyerson LA, Reaser JK (2002a) Biosecurity: moving toward a comprehensive approach. Bioscience 52:593-600

Meyerson LA, Reaser JK (2002b) A unified definition of biosecurity. Science 295:44
Meyerson LA, Reaser JK (2003) Bioinvasions, bioterrorism, and biosecurity. Front Ecol Environ 1:307-314

Meyerson FAB, Meyerson LA, Reaser JK (2009) Biosecurity from the ecological perspective: developing a more comprehensive approach. Int J Risk Assess Manag 12:147-160. https://doi.org/10.1504/IJRAM.2009.025916

Meyerson LA, Carlton JT, Simberloff D, Lodge DM (2019) The growing peril of biological invasions. Front Ecol Environ. https://doi.org/10.1002/fee.2036

Morisette JT, Reaser JK, Cook GL, Irvine KM, Roy HE (2019) Right place. Right time. Right tool: guidance for using target analysis to increase the likelihood of invasive species detection. Biol Invasions. https://doi.org/10.1007/s10530019-02145-z

National Invasive Species Council (2016) 2016-2018 National Invasive Species Council management plan. National Invasive Species Council, Washington, DC

Reaser JK, Burgiel SW, Kirkey J, Brantley KA, Veatch SD, Burgos-Rodríguez J (2019a) The early detection of and rapid response (EDRR) to invasive species: a conceptual framework and federal capacities assessment. Biol Invasions. https://doi.org/10.1007/s10530-019-02156-w

Reaser JK, Simpson A, Guala GF, Morisette JT, Fuller P (2019b) Envisioning a national invasive species information framework. Biol Invasions. https://doi.org/10.1007/ s10530-019-02141-3

Reaser JK, Frey M, Meyers NM (2019c) Invasive species watch lists: guidance for development, communication, and application. Biol Invasions. https://doi.org/10.1007/ s10530-019-02176-6

Simberloff D, Parker IM, Windle PN (2005) Introduced species policy, management, and future research needs. Front Ecol Environ 3:12-20

US Department of the Interior (2016) Safeguarding America's lands and waters from invasive species: a national framework for early detection and rapid response. US Department of the Interior, Washington, DC

Wallace RD, Bargeron IV CT, Reaser JK (2019) Enabling decisions that make a difference: guidance for improving access to and analysis of invasive species information. Biol Invasions. https://doi.org/10.1007/s10530-019-02142-2

Publisher's Note Springer Nature remains neutral with regard to jurisdictional claims in published maps and institutional affiliations. 